\title{
Evaluation of Properties of Dikiri Pulp in the Formulation of Jam
}

\author{
K.D.P.P. Gunathilake* and D.N.H. Samarasinghe
}

\begin{abstract}
The peculiar farm of coconut," Dikiri" was studied for its kernel composition including pectin content with the objective of developing a jam out of Dikiri kernel. Three levels of Dikiri pulp, 20\%, $30 \%$ and $40 \%$, were evaluated to prepare Dikiri based jam. Two types of jam were prepared; Jam made with Dikiri only as the fruit pulp and the jam with Dikiri pulp together with $10 \%$ pineapple. They were tested for sensory attributes and were compared with pineapple jam prepared with added commercial high methoxyl pectin. The best jam was selected for shelf life study at room temperature. Results showed that Dikiri kernel differs from ordinary coconut for all the variables tested in proximate composition analysis. Dikiri kernel contained $16.6 \%$ of high methoxyl pectin on a dry weight basis. The jam with $30 \%$ Dikiri pulp was selected as the best total pulp ratio and the incorporation of $10 \%$ pineapple pulp into Dikiri gives better sensory properties compared with Dikiri only jam. In conclusion, there is a possibility of formulation of jam without adding external pectin with considerable sensory acceptability and good keeping quality.
\end{abstract}

Keywords: Dikiri, kernel composition, coconut jam

\section{Introduction}

Dikiri is a peculiar farm of coconut found in southern areas like in Sri Lanka. It is a coconut in an abnormal state and there are few other types of coconuts from the other coconut growing countries, which are similar to this abnormal form of coconut. "Makapuno", Filled coconut or sport coconut in Philippine," Kalapa Kopjor" in Indonesia, "Thairu Thengia”, curd coconut in India are some peculiar forms of coconut like Dikiri (Ohler,1998).

These peculiar forms of coconut such as Dikiri and Makapuno differ from other normal coconut with a gelatinous endosperm instead of the solid, crispy endosperm and the water (liquid endosperm) found inside ordinary coconuts (Ohler, 1998). Dikiri is a mutant type of coconut found in ordinary bunches. It cannot germinate itself, thus requiring embryo culture techniques to obtain palms with a high proportion of Dikiri fruit just like the Makapuno coconuts (Romulo, 1996). There is a very pleasant taste in the tender gelatinous kernel of Dikiri. It is popular eaten with honey in southern areas of Sri Lanka. Commercially, it is sold fresh to tourists at a good price, but still is not found in the market in processed products.

\footnotetext{
*Department of Food Science \& Technology, Faculty of Livestock, Fisheries \& Nutrition, Wayamba University of Sri Lanka, Makandura, Gonawila, Sri Lanka.

Email: kdppgunathilake@yahoo.com
} 
There are not many studies, but Dikiri has been used experimentally to make ice-cream in research level (Gunathilake et al, 2010). However, there is potential for using it in food processing studies. The gelatinous nature of Dikiri is a sign of its high level of pectin which is very important in food processing. Makapuno in Philippines which bears many similarities to Dikiri has been studied widely. Its endosperm contains a higher level of pectin than ordinary coconuts (Rosario \& Gabuya, 1980) and it is used to produce many types of sweets and frozen dessert. Makapuno ice-cream is a popular dessert in Philippine with a high price (Norberto, 1997).

Dikiri endosperm possesses the same characteristics as Philippine Makapuno. Therefore, the objective of this study was to concentrate on the studies on this peculiar form of coconut and see how it might provide high quality food products to both local and export markets. Apart from developing a jam using Dikiri, this study on its kernel composition may lead to future innovative food processing.

\section{Materials and methods}

\section{Materials}

Dikiri coconut fruit with the same maturity (11 months) were obtained from well maintained home garden in Weligama, southern Province of Sri Lanka, from which six nuts were randomly selected for chemical analysis. Twenty five uniformly mature (11 months) normal coconuts (Sri Lanka Tall) were collected from the same harvest of Bandirippuwa Estate, a section of the Coconut Research Institute, Sri Lanka. Six nuts were randomly selected and used as sample nuts.

\section{Proximate Composition}

Moisture, Protein, lipid, ash and crude fibre contents were determined following the standard methods of the Association of Official Analytical Chemists (1990). Total Carbohydrate content was calculated from the difference. All samples were analyzed at last in triplicate.

\section{Isolation and Characterization of Pectin}

Pectin was extracted and isolated from defatted Dikiri kernel using the acid extraction method described in Sudhakar and Maini (1995).
Defatted kernel was blended with water (1:10 $\mathrm{w} / \mathrm{v}$ ) and the extraction was carried out for two hours at $65^{\circ} \mathrm{C}$ by adjusting the $\mathrm{pH}$ to 1.34 with concentrated hydrochloric acid. Then the extract was collected and was mixed with $95 \%$ ethanol and left 16 hours for the precipitation of pectin. Then the precipitate was separated and washed with acidified ethanol, then absolute ethanol followed by drying at $40^{\circ} \mathrm{C}$. Moisture, ash percentage, equivalent weight, methoxyl value and acetyl values of extracted pectin and commercial pectin were determined using the methods described by Ranganna (1986).

\section{Formulation of jam}

Dikiri based jam were prepared according to the recipe developed based on preliminary trials and citric acid was used as the acidulant to reduce the $\mathrm{pH}$ below 3.1. Sugar was used to maintain the brix value at $65^{\circ}$. In order to determine the level of Dikiri pulp in the jam, three samples were prepared with different pulp ratios $\left(20 \%\left(\mathrm{~T}_{1}\right), 30 \%\left(\mathrm{~T}_{2}\right)\right.$ and $40 \%\left(\mathrm{~T}_{3}\right)$. The best Dikiri pulp level was selected based on a sensory panel. Based on the selected pulp ratio, two types of jams were prepared (Dikiri only, Dikiri: pineapple; 90\%:10\%) (Table 1). Samples were prepared without adding commercial pectin externally. Briefly, Dikiri kernel was scooped weighed and blended with water (1: $1.5 \mathrm{w} / \mathrm{v})$ and was boiled and sugar caramel was added while heating to get the required colour. The boiling of jam mixture was continued until it gets $65^{\circ}$ and food grade citric acid was incorporated to get the required acidity. At the correct consistency the mixture was filled into sterilized bottles while the product is hot higher than $80^{\circ} \mathrm{C}$ and was stored at room temperature. Pineapple jam prepared with commercial pectin was used for the comparison.

Table 1. Raw material composition of Dikiri based jams

\begin{tabular}{|l|c|c|}
\hline Raw material & Dikiri Jam & $\begin{array}{c}\text { Dikiri-Pineapple } \\
\text { jam }\end{array}$ \\
\hline Dikiri pulp \% & 37 & 33.87 \\
Pineapple \% & - & 3.70 \\
Sugar \% & 62.15 & 61.6 \\
Citric acid \% & 0.85 & 0.83 \\
\hline
\end{tabular}




\section{Sensory Evaluation}

Dikiri jam, Dikiri-pineapple jam and Pineapple jam were evaluated for sensory attributes, colour, aroma, texture, taste and overall acceptability using 30 semi-trained panellists. Five point hedonic scales were used for the study.

\section{Shelf life study}

Total soluble solid levels, $\mathrm{pH}$, titratable acidity and total microbial counts were monitored monthly in a period of three months storage.

\section{Statistical Analysis}

The data were analyzed and the means and SD were calculated. Mean comparison was done using analysis of variance and independent sample t-test using SPCC 10 Statistical package (SPSS, Inc, Chicago, IL)

\section{Results and discussion}

According to the table 2, there is a significant difference $(P>0.05)$ in all the constituents between Dikiri and ordinary coconuts. Dikiri kernel has significantly higher values for moisture and carbohydrates $(68.7 \%$ and $38.95 \%)$ than ordinary coconut $(43.6 \%$ and $11.03 \%)$ while ordinary coconut showed a significantly higher amount fat $(66.11 \%)$ than Dikiri . Dikiri kernel values of $17.66 \%, 6.75 \%$ and $2.13 \%$ of fibre, protein and ash respectively are significantly different from those in ordinary coconut $(14.83 \%, 6.14 \%$ and $1.86 \%)$.

It is a good character of Dikiri to have a lower amount of fat than the ordinary coconut in jam making, to reduce the risk of rancidity in storage.

\section{Quality of Dikiri Pectin}

Dikiri coconut contain a considerable amount of pectin $(17.85 \%$ on dry basis) compared to other fruit sources such as passion fruit rind ( $16.1 \%)$ and guava $(6.5 \%)$ on dry basis (Sudhakar and Maini,1995). However, the yield of pectin could vary with degree of ripening and the method of extraction (Malanganie and Gamlath, 2001). There was no significant difference in ash content between Dikiri and commercial pectin $(0.84 \%$ and $0.86 \%)$. However, Miyamati and Chang, (1992) have mentioned that the use of acid and ethanol in pectin extraction may lead to a low content of ash. Comparison of physico-chemical properties of Dikiri pectin and commercial high methoxyl pectin are given in Table 3 .

The extent of the galacturonic acid residues esterified with methanol is defined as the Methoxyl content or the degree of esterification. It determines the solubility, setting time and gelation requirement of pectin (Malanganie and Gamlath, 2001). Acetyl values of Dikiri and commercial pectin are about $0.09 \%$ and $0.07 \%$ respectively. Those values were low compared with sugar beet pectin which contained 21-23\% acetyl content (Michel et al, 1985). The high acetyl content pectin may adversely affect the functional properties such as solubility, pregelation and brittleness (Miyamati and Chang, 1992). It is reported that acid extracted pectin contained a lower amount of acetyl groups than ammonium oxalate or EDTA extraction procedures (Phathak et al., 1988). The equivalent weight of Dikiri pectin (990.98) is comparable with commercial pectin (836.84) as well as with guava fruit (949.00) (Sudhakar and Maini, 1995).

\section{Preliminary study}

There was a significant difference in texture and taste among jams with different pulp ratios $(\mathrm{p}<0.05)$ (Table 4). According to the mean score values, $\mathbf{T}_{\mathbf{2}}$ was selected as the best jam with 30\% total Dikiri pulp.

\section{Sensory evaluation}

There was a significant difference among all the attributes in jam samples with Dikiri, Dikiri mixed with pineapple and the control.

Statistical analysis of scores for sensory evaluation of the jam of $\mathrm{C}_{1}, \mathrm{C}_{2}$ and $\mathrm{C}_{3}$ shows that the differences between treatments were significant in terms of all the attributes. Out of three jam samples, control got the highest mean score values for all the attributes except for texture. Pineapple mixed Dikiri jam was better than the jam with Dikiri only in terms of all the sensory attributes. According to the comments 


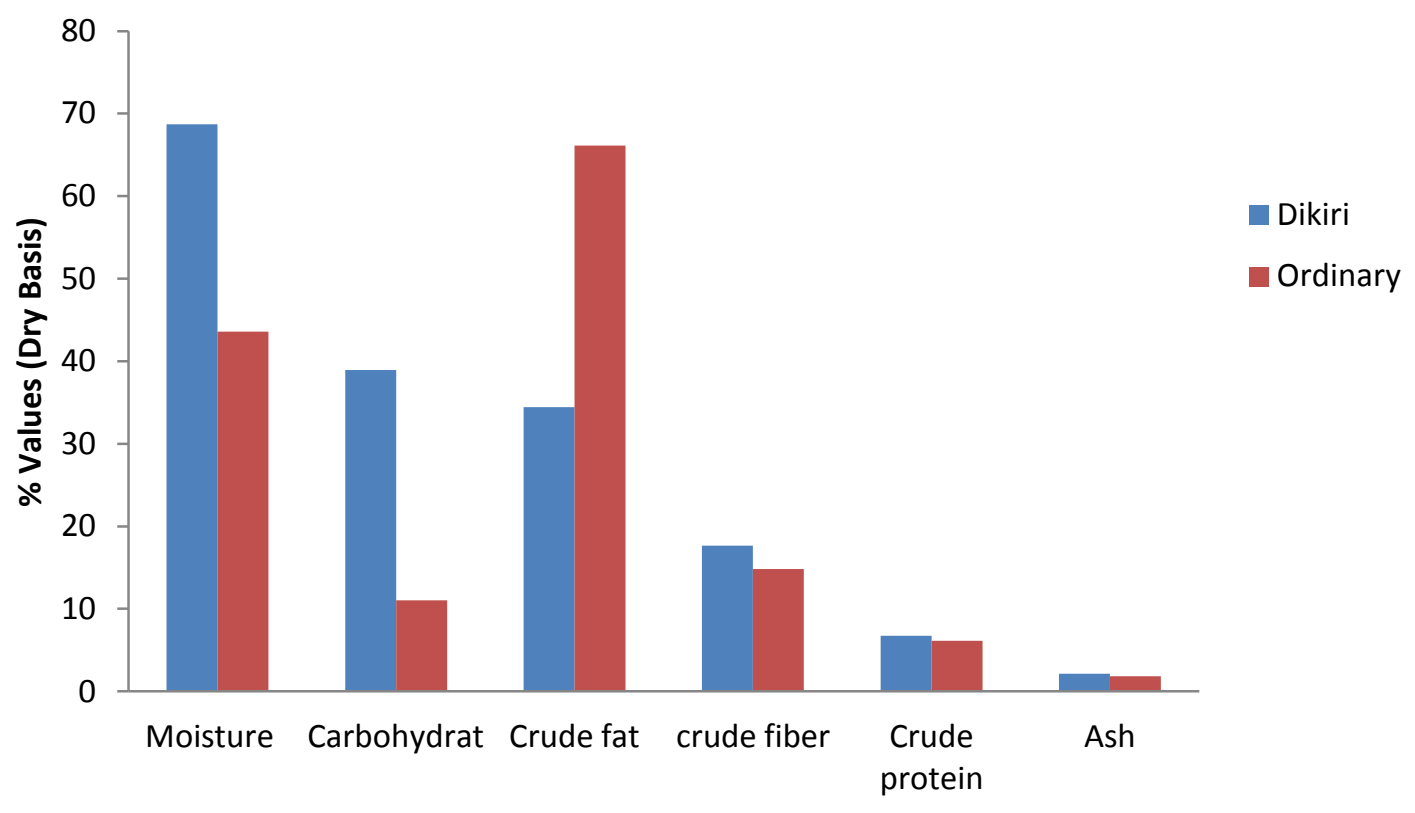

Constituents

Figure 1. Proximate composition of matured Dikiri and ordinary coconut kernel

Table 2. Proximate composition of matured Dikiri and ordinary coconut kernel

\begin{tabular}{|l|l|l|}
\hline \multicolumn{1}{|c|}{ Constituent } & \multicolumn{1}{c|}{ Dikiri } & \multicolumn{1}{c|}{ Ordinary } \\
\hline Moisture & $68.7^{\mathrm{a}}$ & $43.6^{\mathrm{b}}$ \\
\hline Carbohydrate $(\mathrm{db})^{*}$ & $38.95^{\mathrm{a}}$ & $11.03^{\mathrm{b}}$ \\
\hline Fat $(\mathrm{db})^{*}$ & $34.45^{\mathrm{a}}$ & $66.11^{\mathrm{b}}$ \\
\hline Fibre $(\mathrm{db})^{*}$ & $17.66^{\mathrm{a}}$ & $14.83^{\mathrm{b}}$ \\
\hline Protein $(\mathrm{db})^{*}$ & $6.75^{\mathrm{a}}$ & $6.14^{\mathrm{b}}$ \\
\hline Ash $(\mathrm{db})^{*}$ & $2.13^{\mathrm{a}}$ & $1.86^{\mathrm{b}}$ \\
\hline
\end{tabular}

$(\mathrm{db})^{*}$ - Dry Basis. Values in the same row followed by the same subscripts are not significantly different $(\mathrm{P}>0.05)$

Table 3. Physico-chemical properties of Dikiri pectin and commercial pectin

\begin{tabular}{|l|l|l|l|l|}
\hline & \multicolumn{1}{|c|}{ Ash \% } & \multicolumn{1}{|c|}{$\begin{array}{c}\text { Methoxyl } \\
\text { Content \% }\end{array}$} & \multicolumn{1}{|c|}{ Acetyl value \% } & \multicolumn{1}{c|}{$\begin{array}{c}\text { Equivalent } \\
\text { Weight }\end{array}$} \\
\hline Dikiri Pectin & $0.84 \pm 0.007$ & $11.42 \pm 0.13$ & $0.09 \pm 0.001$ & $900.98 \pm 11.48$ \\
\hline Commercial Pectin & $0.86 \pm 0.007$ & $9.58 \pm 0.04$ & $0.07 \pm 0.00$ & $836.84 \pm 4.96$ \\
\hline
\end{tabular}


Cord 2015, 31 (2)

Table 4. P values and mean score of sensory attributes of Dikiri jam

\begin{tabular}{|c|c|c|c|c|}
\hline \multirow[b]{2}{*}{ Attribute } & \multirow[b]{2}{*}{ P Value } & \multicolumn{3}{|c|}{ Mean score } \\
\hline & & $\mathbf{T}_{1}$ & $\mathbf{T}_{2}$ & $\mathbf{T}_{3}$ \\
\hline Texture & $<0.0001$ & 3.1 & 4.3 & 2.0 \\
\hline Taste & $<0.0001$ & 3.9 & 4.5 & 2.4 \\
\hline
\end{tabular}

Table 5. $\mathbf{P}$ vales and mean score of sensory attributes of jam samples

\begin{tabular}{|c|c|c|c|c|}
\hline \multirow{2}{*}{ Attribute } & \multirow{2}{*}{ P Value } & \multicolumn{3}{|c|}{ Mean score } \\
\cline { 3 - 5 } & $<0.0001$ & $\mathbf{C}_{\mathbf{1}}$ & $\mathbf{C}_{\mathbf{2}}$ & $\mathbf{C}_{\mathbf{3}}$ \\
\hline Colour & $<0.0001$ & 2.2 & 3.7 & 4.50 \\
Aroma & $<0.0001$ & 3.3 & 3.2 & 4.07 \\
Taste & $<0.0262$ & 3.87 & 4.1 & 4.60 \\
Texture & $<0.0001$ & 3.1 & 3.2 & 3.73 \\
Overall & & & 3.9 & 4.50 \\
\hline
\end{tabular}

Table 6. Physicochemical properties of Dikiri-Pineapple jam

\begin{tabular}{|c|c|c|c|c|}
\hline DAP & $\begin{array}{c}\text { Titrable acidity } \\
(\boldsymbol{\%})\end{array}$ & $\mathbf{p H}$ & Brix $^{\mathbf{0}}$ value & $\begin{array}{c}\text { Total plate count } \\
(\mathbf{c f u} / \mathbf{g})\end{array}$ \\
\hline 0 & 0.66 & 3.05 & 65 & $1 \times 10^{1}$ \\
30 & 0.66 & 3.10 & 65 & $2 \times 10^{1}$ \\
60 & 0.67 & 3.12 & 65 & $2 \times 10^{1}$ \\
90 & 0.65 & 3.09 & 65 & $3 \times 10^{1}$ \\
\hline
\end{tabular}

DAP $=$ Days after production 
made by the panellists, there should be improvements in colour and aroma of Dikiri jams. According to some panellists, the reason for giving low marks for the colour of jam was due to the lower transparency of Dikiri jam than the pineapple jam. Also the oily aroma of Dikiri jam did not attract many of the panellists.

\section{Shelf-life studies of Dikiri-pineapple jam}

According to the result obtained for physicochemical studies done of the characters of Titrable acidity, $\mathrm{pH}$ and brix value showed that there was not much change in those measurement for three months in the DikiriPineapple jam stored at room temperature. Also, the total microbial count was below $3 \times 10^{1} \mathrm{cfu} / \mathrm{g}$ during that period.

\section{Conclusion}

According to the results of proximate composition analysis Dikiri kernel is significantly different from ordinary coconut for all the variables of moisture, crude protein, crude fat, crude fibre, total ash and carbohydrates. Pectin analysis of Dikiri showed it has a considerable amount of high Methoxyl pectin (16.6\% on dry basis). This indicates a good possibility of making jam using Dikiri without adding external pectin. The jam was good in terms of sensory attributes of taste and texture, but according to the sensory evaluation it should be improved further for colour and aroma. Storage studies showed that Dikiri-Pineapple jam can be stored at room temperature for at least three months without any significant change in physico-chemical characters. The jam was safe in terms of microbial count.

\section{Acknowledgment}

Authors wish to offer their sincere thanks to the staff of the Coconut Processing Research Division, Coconut Research Institute, Lunuwila for the assistance provided throughout the research project.

\section{References}

Anon (1999). SAS/STAT software, institute inc. Cary, NC 27513, USA.
Gunathilake, K.D.P.P., Javidh, M.A.M., Perera, G.R.P.K., Thilakhewa, C. and Kumara, A.A.N. (2010). Value added products from Dikiri coconuts; preparation, compositional and sensory qualities. CORD, International Journal on Coconut $\mathrm{R} \& \mathrm{D}, 26(2)$

Kordylas J.M. (1990). Processing and preservation of tropical and subtropical fruits. Macmillian pub.co. Inc., New Delhi.

Malanganie K.G.P. and G.G.S Gamlath. (2001). Properties of pectin isolated form Lavulu (Crysophylum roxbergy G Don) and development of jam and fruit leather using Lavulu and pineapple. $\mathbf{J}$ of Tropical Agriculture, 13:51-61.

Michel F., Thibault J.F., Mercier C., Heitz F. and Povitecnde F. (1985) Extraction and characterization of pectin from sugar beet pulp.J food Sci.50:1499.

Miyamati A. and Chang K.C. (1992). Extraction and Physico-chemical characterization of pectin from sunflower head reduces. J food Sic. 57:1439-1442.

Norberto M.B. (1997). Market prospects of Makapuno. J. Cocoinfo Int, 4(2):25-27

Ohler J.G. (1998). Some peculiar form of coconut. J. Food and Agriculture Organization. Rome, 57:86-87

Phatak L., Chang K.C. and Brown G. (1988). Isolation and characterization of pectin in sugar beet pulp. J. Food Sci. 53 (3): 830833.

Ranganna S. (1986). Hand book of Analysis and Quality Control of fruit and vegetable Products. Tata McGraw-Hill pub. Co., Ltd., New Delhi, Mayapuri.

Romulo N.A.J. (1996) Makapuno from the Philippines. J. Coco info Int, 3(1):15-17

Rosario R.R. and E.S. Gabuya. (1980). Preliminary studies on the polysaccharide composition of coconut and Makapuno cell wall. J. Philippine journals of coconut studies, 5, 1(June):17-23. 
Cord 2015, 31 (2)

Sudhakar D.V. and Maini S.B. (1995) form fruit processing waste. J. Indian Food Packer. 49(1):39-56. 